\title{
ANALISIS FAKTOR INTERNAL, EKSTERNAL DAN RESOURCE - BASED VIEW STRATEGI PT XYZ DALAM MEMENANGKAN PERSAINGAN DALAM INDUSTRI TIMBANGAN
}

\author{
Teguh Halim \\ Program Studi Magister Manajemen Universitas Tarumanagara \\ teguh.halim.rvn@gmail.com \\ Masuk : 07-12-2019, revisi : 21-12-2019 diterima untuk diterbitkan : 23-12-2019
}

\begin{abstract}
A qualitative research by direct, extensive observation and thorough interview with PT XYZ's (weighing industry company) high - level manager to analyse internal factor (strength and weakness), external factor (opportunity and threat) using Resource - Based View and SWOT Analysis to implement strategy with intention to win the competition in weighing industry. The conclusion of this research is PT XYZ implement Forward Integration, Market Development and Product Development as their strategy in the future to maximize the company strength.
\end{abstract}

\begin{abstract}
Abstrak : Sebuah penelitian kualitatif dengan observasi secara langsung dan mendalam serta wawancara secara menyeluruh dengan manajer tingkat tinggi dari PT XYZ (perusahaan industry perusahaan) untuk menganalisa faktor internal (kekeuatan dan kelemahan), faktor eksternal (kesempatan dan ancaman) menggunakan Pendekatan Resource - Based View dan analisa SWOT untuk mengimplementasikan strategi dengan tujuan untuk memenangkan persaingan dalam industri timbangan. Kesimpulan dari penelitian ini adalah PT XYZ menerapkan Integrasi ke depan, pengembangan pasar, dan pengembangan produk sebagai strategi mereka di masa depan untuk memaksimalisasi keunggulan dari perusahaan
\end{abstract}

Keywords : Resource - Based View (RBV); SWOT Analysis; Internal Factor; External Factor; Industri Timbangan

\section{PENDAHULUAN}

Dalam kehidupan manusia sehari - hari secara tidak sadar semua aspek kehidupan manusia berkaitan dengan pengukuran, dan keakuratan. Timbangan menjadi alat ukur paling lazim digunakan baik yang sederhana seperti timbangan di pasar tradisional ke timbangan industri berat hingga timbangan laboratorium yang harus benar - benar akurat atau presisi.

PT XYZ adalah perusahaan yang bergerak dalam bisnis timbangan, tidak hanya timbangan untuk mengukur berat tetapi hingga timbangan presisi. PT XYZ juga memiliki pabrik yang memproduksi jembatan timbang untuk mendukung bisnis penjualan timbangan.

Tujuan penelitian agar perusahaan dapat merumuskan strategi dengan lebih baik sehingga unggul dari pesaing.

Ada 3 permasalahan utama dalam memfokuskan penelitian ini yang terdiri dari:

1. Apa saja faktor internal dan faktor eksternal yang dimiliki oleh PT XYZ dengan menggunakan Internal Factor Evaluation dan External Factor Evaluation?

2. Apa saja sumber daya (resources) dan kompetensi (capabilities) yang dimiliki oleh PT XYZ dengan menggunakan Resources - Based View (RBV)?

3. Setelah mengetahui faktor internal, faktor - faktor eksternal, sumber daya dan kompetensi dari PT XYZ, Strategi Bisnis apa yang paling tepat untuk terapkan dan dikembangkan oleh PT XYZ untuk menciptakan competitive advantage, guna memenangkan persaingan dalam industrinya? 


\section{STRATEGI, INTERNAL DAN EKSTERNAL MATRIX, SWOT ANALYSIS, RBV}

Menurut Pearce dan Robinson, (2013), strategi dari perusahaan harus sejalan dengan goal dari perusahaan tersebut. Strategi yang baik tidak boleh hanya berfokus pada satu komponen dalam perusahaan saja melainkan harus mencakup dan integrasikan seluruh lini perusahaan, dari sektor operasional, produksi, keuangan, marketing, $R \& D$, dll.

Menurut David (2009) dalam bukunya Strategic Management Concept \& Cases menjelaskan bahwa IFE Matrix adalah alat untuk mengevaluasi strength \& weakness dari suatu perusahaan dan mengidentifikasi serta mengevaluasi hubungan dari semua area bisnis perusahaan untuk merumuskan strategi yang terbaik untuk perusahaan tersebut. Penyusunan IFE Matrix terdiri dari 5 tahap yakni:

1. Tentukan internal faktor dari perusahaan tersebut termasuk strength \& weakness perusahaan tersebut sespesifik mungkin dengan menggunakan rasio, dll.

2. Tentukan bobot dari setiap faktor - faktor internal yang sebelumnya telah ditentukan mulai dari 0,0 (tidak penting) sampai 1,0 (paling penting). Bobot yang telah ditentukan untuk setiap faktor tersebut mengindikasikan pentingnya faktor tersebut dalam keberhasilan perusahaan, baik faktor tersebut merupakan weakness ataupun juga strength, faktor yang paling penting harus diberi bobot yang paling besar, dan jumlah kesemua faktor tersebut harus sama dengan 1 (satu).

3. Berikan rating pada tiap faktor dengan dengan interval 1 - 4 dimana: Rating 1 (Sangat Lemah), Rating 2 (Lemah), Rating 3 (Kuat), Rating 4 (Sangat Kuat).

4. Kalikan rating dengan bobot dari setiap faktor untuk mendapatkan skor dari setiap variabel.

5. Jumlahkan skor tersebut untuk mendapatkan skor total (total score).

Selain IFE matriks, EFE Matrix juga perlu mendapat perhatian. EFE matrix adalah suatu alat bagi perusahaan untuk untuk mengevaluasi faktor eksternalnya seperti keadaan ekonomi, sosial, politik, hukum, dll untuk bisa mengformulasikan Opportunities dan Threat dari perusahaan tersebut. Penyusunan EFE Matrix terdiri dari 5 tahap yakni:

1. Tentukan internal faktor dari perusahaan tersebut termasuk opportunities \& threats perusahaan tersebut sespesifik mungkin dengan menggunakan rasio, dll.

2. Tentukan bobot dari setiap faktor - faktor internal yang sebelumnya telah ditentukan mulai dari 0,0 (tidak penting) sampai 1,0 (paling penting). Bobot yang telah ditentukan untuk setiap faktor tersebut mengindikasikan pentingnya faktor tersebut dalam keberhasilan perusahaan, opportunities umumnya mendapatkan bobot yang lebih besar dari threats namun tidak menutup kemungkinan threats mendapatkan bobot yang lebih besar bila threats tersebut benar besar dan berpengaruh pada perusahaan secara keseluruhan dan jumlah kesemua faktor tersebut harus sama dengan 1 (satu).

3. Berikan rating pada tiap faktor dengan dengan interval $1-4$ dimana: $4=$ The response is Superior, $3=$ the response is above average, $2=$ the response is average, $1=$ the response is poor. Strength harus menempati rating 3 dan 4 sedangkan weakness harus menempati rating 1 dan 2.

4. Kalikan rating dengan bobot dari setiap faktor untuk mendapatkan skor dari setiap variabel.

5. Jumlahkan skor tersebut untuk mendapatkan skor total (total score).

Selain metode di atas, Barney (1991: 99 - 120) juga memberikan ususlan pentingnya penggunaan metode RBV (resource Based View). RBV ini menitikberatkan pada bagaimana suatu perusahaan meningkatkan performanya dengan mengidentifikasi dan memanfaatkan internal resources dengan baik dan internal resources tersebut harus unik dan sulit ditiru sehingga sulit untuk diterapkan oleh perusahaan lain. Dari peningkatan performa tersebut maka perusahaan akan memiliki competitive advantage. SWOT Matrix apa yang menjadi kekuatan 
dan kelemahan dari suatu perusahaan sehingga perusahaan tersebut dapat memanfaatkan peluang yang ada dan menangkal ancaman yang akan dihadapi perusahaan.

Penulis melakukan wawancara langsung dengan high-level management dari PT XYZ antara lain dengan GM, Manager dari divisi marketing, teknik, keuangan dan sumber daya manusia dan observasi langsung ke Head Office PT XYZ. Dan juga melakukan penyebaran kuesioner ke beberapa GM dan Manager untuk membantu penulis dalam mengetahui hal - hal yang dianggap krusial dan penting dalam perusahaan. Kemudian penulis dapat menentukan faktor eksternal dan internal mana saja yang dianggap penting setelah IFE dan EFE telah diketahui penulis melakukan analisa sumber daya perusahaan, baik tangible asset maupun intangible asset dari PT XYZ dari situ penulis dapat menetapkan strategi untuk PT XYZ.

\section{HASIL DAN PEMBAHASAN}

Strength : keadaan Keuangan yang baik,Hubungan baik dengan bank, Penerimaan pembayaran dari customer yang baik, Produk yang dijual berkualitas premium, Memiliki hubungan baik dengan group - group besar di Indonesia (0.07), Memiliki layanan purnajual yang baik dengan Maintenance Contract yang terpercaya (0.1), Memiliki cabang hampir diseluruh pulau besar di Indonesia (0.05), Pengalaman perusahaan yang baik karena sudah berdiri lebih dari 60 tahun, Memiliki Pabrik Produksi Jembatan Timbang sendiri (0.1), Teknisi yang terlatih (0.07), Level Manager ke atas diisi oleh orang yang berpengalaman dan latar belakang pendidikan yang baik.

Weakness : Sistem program finance perusahaan yang ketinggalan jaman, produk yang dijual PT XYZ premium maka sulit bagi perusahaan kecil untuk membeli produk PT XYZ, kurangnya new customer di PT XYZ, Gaya kepemimpinan yang sangat tersentralisasi terhadap Kantor Pusat (0.08), Pemberian uang dinas yang kurang memadai, Karyawan di cabang belum semua S1, Kurang tenaga Sales yang berpengalaman karena turnover yang tinggi (0.08).

Opportunities : Sedang melakukan penerapan sistem financing perusahaan, Keadaan keuangan perusahaan yang baik membuat perusahaan lebih mudah untuk ekspansi, Timbangan Retail terus meningkat permintaannya seiring dengan makin banyaknya toko - toko retail, whole-seller dan convenience store yang buka (0.12), AWT sebagai principal utama dari PT XYZ memiliki banyak proyek di luar Indonesia dan PT XYZ sudah mulai melaksanakan proyek - proyek di luar negeri terutama di Afrika dan SEA, Depo Pontianak yang selama ini masih dikontrol oleh cabang Jakarta akan diubah menjadi cabang mandiri (0.15), Perusahaan bisa lebih banyak lagi melakukan training bagi karyawannya.

Threat : Harga Dollar yang tinggi, Produk dari China sudah mulai menggerogoti pasar karena harga yang murah (0.15), PT XYZ adalah agen tunggal dari AWT namun kenyataannya ada perusahaan lain yang dapat memasok produk AWT ke Indonesia, Teknisi dari PT XYZ banyak yang resign dan pindah ke customer PT XYZ sehingga customer tersebut dapat melakukan servis tanpa melalui PT XYZ (0.12).

SWOT yang dicetak tebal merupakan yang paling berpengaruh dan angka dalam kurung adalah bobot yang tetap oleh manajemen perusahaan. Dari hasil wawancara tersebut penulis menyebarkan kuesioner untuk memberikan rating terhadap masing - masing SWOT tadi yang diisi oleh top-level management dari PT XYZ. Kemudian rata - rata ratingnya di kalikan dengan bobot yang ditetapkan tadi sehingga bisa ditetapkan berada di bagian mana PT XYZ berada dalam Internal \& External Matrix diagram dan hasilnya adalah 2.83 untuk IFE Matrix dan 3.06 untuk EFE Matrix. 


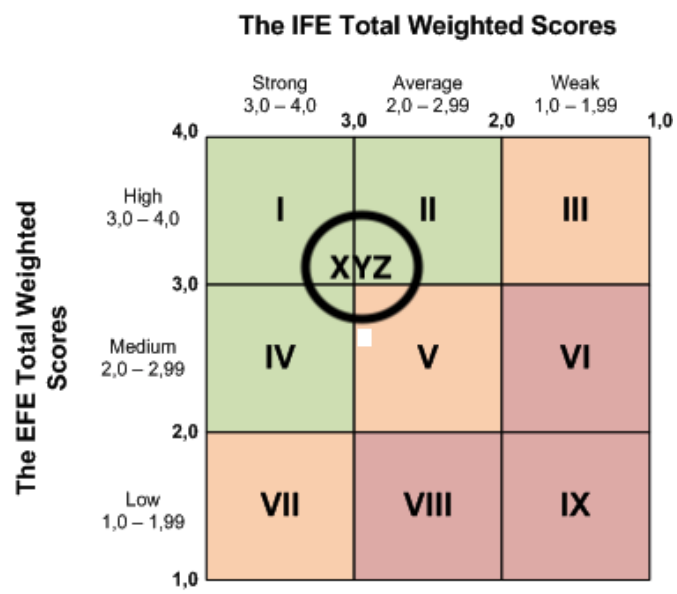

\section{Gambar 1 Posisi PT XYZ dalam Internal \& Eksternal Matrix}

Penulis menggunakan pendekatan RBV dalam merumuskan strategi bisnis bagi PT XYZ. Metode pendekatan RBV yang digunakan penulis adalah metode yang telah dirumuskan oleh Grant (2001 : 1-2). Dalam jurnalnya yang berjudul "The Resource Based Theory of Competitive Advantage: Implications for Strategy Formulation” Grant menawarkan satu pendekatan sederhana dalam merumuskan strategi bisnis melalui pemaksimalan sumber daya dan kompetensi internal perusahaan.

Berdasarkan uraian sumber daya yang dimiliki oleh PT XYZ di atas, maka dapat disimpulkan bahwa terdapat tiga kompetensi utama yang dapat dilakukan PT XYZ dengan sangat baik, yaitu:

\section{Produk dan Servis yang bagus}

Cabang yang terletak di Medan sampai Makassar membuat PT XYZ lebih dapat menjangkau customer dan mengerjakan proyek dengan lebih cepat dan baik, teknisi yang terlatih dan berkualitas serta produk dan software yang sangat customizable sehingga dapat dibuat persis dengan keinginan customer.

\section{Brand Awareness dan Customer Database yang baik}

PT XYZ sudah lama berbisnis dalam industri ini yakni lebih dari 50 tahun sehingga sudah dikenal secara luas dan produknya yakni AWT sudah terkenal di dunia dengan kualitasnya yang premium.

\section{XYZ Information Center}

XYZ Information Center membuat petinggi dari PT XYZ kemampuan untuk mengontrol kunjungan sales, menilai performa dan penetuan komisi dari Sales Executive, melihat data customer, mencari perusahaan yang potensial menjadi customer baru, mengontrol Maintenance Contract, Logistik dan perlaporan keuangan PT XYZ.

\section{Core Competence \& Competitive Advantage Analysis}

Sumber daya (resource) dan kompetensi (capabilities) yang telah diuraikan di atas menjadi salah satu modal utama PT XYZ dalam membentuk keunggulan kompetitif (competitive advantage). Berdasarkan uraian diatas, maka disimpulkan bahwa terdapat beberapa hal yang menjadi keunggulan PT XYZ, yaitu:

1. Produk yang dimiliki PT XYZ yakni AWT menawarkan kualitas produk yang premium dan sangat baik dengan tingkat keamanan yang tinggi serta software yang customizeable, pabrik jembatan timbang yang bisa membuat jembatan timbang custom sesuai dengan kebutuhan customer dan juga dengan 9 cabang yang tersebar mulai dari Medan sampai Makassar membuat customer mendapat servis lebih cepat.

2. Teknisi yang terlatih yang juga memiliki kemampuan dasar teknik sipil bukan hanya elektrik sehingga bisa menemukan masalah dilapangan lebih tepat dan cepat. Teknisi 
yang terlatih ini pula yang menjadi keunggulan PT XYZ dalam memasarkan Maintenance Contract-nya sebagai aftersales servis perusahaan dimana customer yang puas akan memperpanjang terus Maintenance Contract demi kelancaran kegiatan operasional customer tersebut.

3. XYZ Information Center yang mampu memberikan data mendalam mengenai Sales Performance, Customer Prospect yang dapat dengan menyeluruh mengetahui kebutuhan dari pelanggan, tidak hanya itu XYZ Information Center dapat menilai performa sales mulai dari daftar kunjungan sales, pencapai target sales dan perhitungan komisi sales. serta mengolah internal perusahaan yakni Logistik serta Finance and Accounting.

Penulis menggabungkan metode RBV dengan hasil yang telah diperoleh melalui IFE Matrix dan EFE Matrix dengan IE Matrix. Ketiga metode ini akan menghasilkan strategi yang dapat digunakan oleh PT XYZ guna mencapai keunggulan kompetitif. Dan strategi yang didapat adalah: Forward Integration dengan memproduksi juga jembatan timbang untuk customer diluar customer PT XYZ dan mengerjakan fondasi jembatan timbang. Market Development membuat cabang mandiri di Pontianak agar dapat memperluas sales area perusahaan. Product Development dengan memasarkan produk elektronik jembatan timbang selain AWT.

\section{KESIMPULAN DAN SARANNYA}

Berdasarkan hasil penelitian diperoleh kesimpulan sebagai berikut:

1. Dari hasil analisis dengan metode IFE, EFE dan IE Matrix, PT XYZ mempunyai faktor internal dan eksternal, yang berada pada kuadran Grow \& Build, dengan nilai IFE $=2,83$ dan $\mathrm{EFE}=3,06$.

2. Keuntungan bersaing yang dimiliki PT XYZ adalah memiliki pabrik jembatan timbang sendiri, layanan purnajual (Maintenance Contract) yang baik dan memiliki cabang di hampir seluruh pulau besar di Indonesia.

3. Alternatif strategi yang cocok digunakan PT XYZ adalah Forward Integration, Market Penetration, Market and Product Development.

\section{DAFTAR PUSTAKA}

Barney, J.B. (1991). Firm Resources and Sustained Competitive Advantage. Journal of Management, 17(1), 99-120.

Barney, J.B. (1997). Gaining and Sustaining Competitive Advantage. Addison-Wesley.

Barney, J.B. (2001). Is Resource-Based 'View' a useful Perspective for Strategic Management Research? Yes. Academy of Management Review, 26(1), 41-56.

Fred R. David, (2006). Manajemen Strategis. Edisi Sepuluh. Jakarta : Salemba Empat.

Grant, R.M. (1995). Contemporer Strategy Analysis : Concept, Technique, Application. Blackwell, Oxford. 